\title{
Thoughts on the Application of Positive Psychology to Overcoming the Learning Disgust of Middle and Primary School Students
}

\author{
Zhang Jinyong \\ School of Education Science, Guizhou Education University, Guiyang, Guizhou 550018, China
}

Key words: Positive Psychology; the Learning Disgust; Primary and middle school students

\begin{abstract}
This paper analyzes the tiredness of primary and secondary school students from the perspective of positive psychology. Positive psychology mainly includes four aspects: positive thinking, positive emotional experience, positive quality and positive social environment. The enlightenment of positive psychology on overcoming the anorexia in primary and middle schools :(1) Learning to make positive cognition of problems; (2) Cultivate the positive emotions of misogynistic experience: Use intuitive and experiential teaching to stimulate learning interest; Use the principle of "nearest development area" to let them experience the sense of achievement. Give positive evaluation in time to enhance their confidence; Leads to correct attribution, stimulates the learning motivation. (3) Cultivate the misogynist with such positive qualities as diligence, optimism and persistence; (4) Create a loose and harmonious social environment for misogynists.
\end{abstract}

\section{Introduction}

Positive psychology research has become a new and emerging psychological trend of thought, whose speed of development and the wide range of influence has inadvertently developed into a worldwide psychology movement. Different to traditional negative psychology, positive psychology focuses on the positive qualities of human development potential and virtue. Psychology is born with three major missions: to treat people's mental or mental illnesses, to help ordinary people live more fulfillingly, to discover and cultivate people with extraordinary talents. Traditional psychology, however, only focuses on the research and restoration of psychological problems since World War II. To a certain extent, it neglects the latter two missions. Therefore, the rise of positive psychology can be a supplement to the development of contemporary psychology, and this makes the one-sided tendency psychology become more comprehensive, more reasonable and more balanced.

As one of the most common mental illnesses among adolescents, leaning disgust now becomes the most common and dangerous problem among many primary and middle school students and the most important factor leading to dropout. According to relevant surveys, $52 \%$ of contemporary primary and middle school students have different levels of disgusting emotions, and nearly $12 \%$ of them are more tired of schooling, which has affected academic performance [1]. In 1998, the "Investigation on the Status of Learning and Development of Primary and Secondary School Students in China" found that only $6 \%$ of students attended school because they "like to learn" and $8.9 \%$ of junior high school students[2]. It can be seen that the phenomenon of middle school students being tired of learning is quite common and serious. Of course, this phenomenon has attracted the attention of the education community and researchers. They analyze the emotions of disgusting from different angles and propose corresponding solutions. In the field of psychology, disgusting is often analyzed from a traditional point of view and just seen as a "problem", but rare researches were conducted from a positive perspective. The rise of positive psychology has provided us with new ideas for solving this problem, and we have extended from a simple "repair" to a further "prevention" methodology.

\section{The main idea of positive psychology}

\subsection{Positive thinking}

Positive psychology advocates individuals to make positive explanations about the difficulties and problems they encounter. In the course of lives, problems are inevitable and appear in the form of 
one kind or another. Someone once said that "life itself is a problem with overlapping problems." When the problem arises, each of us has the freedom to make a reasonable explanation for the problem. Negative treatment does no help and will only make things worse. Therefore, this requires us to look at the problem in a comprehensive and positive way. For bad things, we should see the positive side of it, and look at the problem in a different way. In this way, positive thinking will help us enhance not only the positive emotional experience but also the formation of positive personality.

\subsection{Positive emotional experience}

Positive emotions are all emotions that stimulate individuals to develop close sexual behavior or behavioral tendencies [3]. Some people divide the positive emotional experience into sensory pleasure and psychological enjoyment. The former refers to a subjective experience after the body eliminates its internal internal tension, and belongs to the lower level. Psychological enjoyment comes from the break of some kind of self-balance inherent in the individual, transcending the original state of the individual and a relatively advanced emotional experience. It can be said that the former is the premise and foundation of the latter, and the latter is the advanced form of the former development.

Positive emotions have two major functions. One is the expansion function. Positive psychologist Frederickson's "positive emotion expansion theory" puts that certain positive emotions such as happiness, interest, satisfaction, pride and love have the function of expanding people's short-term thinking behavior. They all improve the creativity and flexibility of thinking in a certain way. Thus the way of dealing with the environment will becomes more positive, and the interpersonal relationship will be improved accordingly. People bring indirect, long-term adaptation values. Generally speaking, negative emotions only have a protective effect on stress, while "positive emotions can encourage individuals to fully take their own initiative, resulting in a variety of thoughts and actions, especially those that generate some creative or creative thoughts and actions. And these thoughts and actions will in return be applied to other aspects" [3].

\subsection{Positive quality}

According to positive psychology research, there are 24 kinds of positive forces such as courage, concern for the future, optimism, interpersonal skills, belief, professional ethics, hope, honesty, perseverance and insight, creativity, etc. A positive force will withstand mental illness. These positive forces are the potential positive qualities of human beings. These positive qualities exist in every individual and can only be fully stimulated if conditions are appropriate. Positive quality is also the content of positive personality. So, what is positive personality? How is it formed? According to the theory of behaviorism, positive qualities are the result of stimulating and strengthening individual realities and potentials of individuals. When a realistic ability or potential ability becomes a habitual way of working, positive personality traits are formed.

\subsection{Active social environment}

Positive psychology advocates an active social system, which mainly includes the state, work units, families, schools and so on. Positive thinking, positive emotions and positive qualities are the internal factors that affect a person's development and quality of life, while an active social environment is an external factor that affects a person's development and quality of life. The social environment is often not something that individual power can change, but it must not be ignored. We should appeal to and focus on the establishment and improvement of an active social environment or system.

\section{The enlightenment of positive psychology on overcoming the learning disgust of primary and middle schools}

How to introduce positive psychology into the education to overcome the school-weariness of primary and secondary schools is an arduous task that requires the joint work of psychologists and 
educators. However, as a response to this new trend of thought and an understanding of its main ideas, we can't help but make some adjustments and changes from the following four aspects to improve our work.

\subsection{Promote a positive explanation of the problem}

Positive psychology advocates individuals to make positive explanations about the difficulties and problems they encounter. In traditional education, teachers often regard students who are tired of learning as "problem" students, even those who are "bad", and rarely see their good side, because they often use the level of achievement as the sole estimated standard. Students who are tired of learning often show inattention and small movements in the classroom due to knowledge defects or other reasons. At this time, teachers often think that "problems" have emerged, and they deal with them through critical education. However, teachers should understand their student from another aspects, even if he does not understand and insist on staying in the classroom. Should it be appropriate to reflect on his own teaching methods? Does the classmate's knowledge have defects? Thinking in this way will not only eases the tension of the teachers themselves, but also helps to explore the root causes of the problem. For example, students who are tired of learning often emerge because of the imbalance in the development of the subject. If a student got 50 points in one exam and 90 points in another, focusing on 50 points will cause his negative emotional experience, and may even lead to its lack of motivation. On the contrary, teachers' encouragement and analyses of the reasons for low score will be more conducive to the solution of the problem. In short, we must not only be good at using positive thinking, but also help students develop the habit of learning to use positive thinking. This will not only get a positive experience from the problem itself, but also help the formation of optimistic character.

\subsection{Cultivate positive emotions}

Cultivating positive emotions is very necessary for primary and secondary school students with a feeling of learning.Tired of learning itself is loaded with a negative emotion. Such students often bear a certain burden of learning and rarely experience happiness, especially the joy of learning. This is largely due to the fact that traditional education focuses on the repair of problems. The more difficult contents they are to learn, the more questions they will ask, and the lower emotions they will have. This leads to a vicious circle. Then how to cultivate positive emotions? Some solutions are put as the following.

\subsubsection{The use of intuitive and experiential teaching to stimulate students'learning interest}

Interest is the best teacher and the intrinsic motivation of students to learn. Tolstoy once said: "Successful teaching does not require coercion, but stimulates students' interest". This sentence is especially suitable for primary and secondary school students who are tired of learning. You can do experiments, look at pictures, visit the field, use multimedia and other forms to teach, stimulate their interest in learning and enhance their positive emotional experience. Chen Chen's research found that the design of experiential career counseling activities based on extreme psychology can reduce students' tiredness in many aspects. This further confirms Dewey's philosophy of "being in middle school" education. [4]

\subsubsection{The use of the principle of "recent development zone" to let students experience the sense of accomplishment}

Primary and secondary school students who are tired of learning tend to have certain knowledge barriers related to the current learning progress. Therefore, according to their specific circumstances, teachers should carefully design some topics in order to achieve the effect of picking up the fruit when they jump. If a student has solved a "difficult" problem through his own efforts, psychologically it will inevitably produce a sense of happiness. This not only gives them an experience of positive emotions, but also promotes their intention to learn to learn.

\subsubsection{Timely positive comments to enhance students' confidence}

Carnegie, the American educator, once said everyone wants to be praised and praised by others. This is in line with human nature. Primary and middle school students who are tired of learning need to be recognized by others, especially the teachers. Even if they make small progress, if the 
teacher can find and give encouragement and recognition in time, a concerned eye or a happy smile will make the students feel happy and spring. If you can't answer a question when you are a student who is tired of learning, the teacher says, "Don't worry, think about it again", "You must have a solution to this problem", etc.which eliminates tension and enhances learning. Confidence is absolutely necessary. [5] Therefore, teachers should strengthen and give positive evaluations when educating students, which should be strongly advocated.

\subsubsection{The establishment of correct attribution and stimulation of learning motivation}

According to Weiner's attribution theory, ability, effort, task difficulty and luck are the four main factors in explaining success or failure. These four factors can be divided into three criteria: internal and external factors, stability and controllability.

Students who are tired of learning are affected by negative emotions. They often attribute the poor academic performance to their own poor ability. Others think that they are not born to learn. Even if they score well, they often think that the problem is easy or they are lucky, not the result of hard work or ability. This also makes it difficult to get a positive emotional experience and often leads to a vicious circle. Therefore, teachers should help them establish the correct attribution model, and then stimulate their inner learning motivation.

\subsection{Inspire positive quality}

People have 24 positive qualities, and they can be classified into six virtues, namely wisdom, courage, benevolence, justice, moderation and excellence. The former two are at their core. Wisdom is more important for primary and secondary school students who are tired of learning. These include curiosity and interest in the world, love learning, creativity, creativity and innovation. The exploration of the world and the thirst for knowledge are the nature of each student, but these natures are suppressed by unreasonable educational systems. This is consistent with the humanistic teaching philosophy--people-oriented and the development of students' potential. As Maslow said, "If education can help individuals to realize their potential and self-realization, that is good." [6] Of course, it is also necessary to stimulate and cultivate the qualities of persistence, diligence, optimism, and hope. There are two main ways to motivate and cultivate these positive qualities: one is to promote positive experiences, and the other is to cultivate high self-esteem. What is self-esteem? To put it simply, self-esteem is a kind of self-evaluation that has been made and long-held. James believes that self-esteem is an experience that individuals experience after they have achieved expectations in some of their important areas of life. Since it is an experience in some fields, we should be good at discovering the strengths and strengths of the boring scholars and helping them to realize that they are not completely useless to enhance their self-esteem. At the same time, James also uses a formula to express self-esteem, that is self-esteem = successful outcome / expectation or ambition. Through this formula, we can improve their self-esteem by reducing the expectations of those who are tired of or helping them to lower their ambitions.

At the same time, positive psychology research has confirmed that those with positive attitudes have better social ethics and better social adaptability than ordinary people, and they can stand pressure, adversity and loss more easily, even if faced. They can cope with the most unfavorable social environment. In this way, you can change your pressure into motivation and become negative and positive. "We want to use the theory of positive psychology to let students know that everyone has the motivation to realize their own value. It is the most important thing to improve according to their own progress. The best way is to motivate students' positive emotions and happiness and enhance the motivation of learning." [7] In short, teachers can adopt the above ways to achieve the purpose of stimulating and cultivating students' positive quality.

\subsection{Create a positive social environment}

Creating an active social environment is also an important measure to reduce or eliminate disgusting emotions. This is also an important concept of positive psychology. Studies by Williams et al. confirm that when teachers provide students with optimal support, compassion, and choice, they are most likely to have good mental health and interpersonal relationships; otherwise, these children are prone to be in unhealthy emotions. [7] From a social point of view, everyone should 
actively appeal to and resist the test-oriented education and actively advocate and practice quality education. The education administrative department should take effective measures to effectively promote the prevailing trend of social training and training, which also brings learning pressure to some primary and middle school students from the outside world. Parents should pay attention to the scientific education method, combine the actual learning situation of the child, and have appropriate expectations. High and far-reaching expectations will only cause unnecessary mental burden to the child. Schools should actively create a relaxed and rich learning environment and a harmonious class, which makes the tired students feel a sense of belonging. Here, it is especially emphasized that teachers should not blindly arrange extracurricular homework and squeeze students' rest and recreation time, which will only lead to students' disgusting feelings. They should pay attention to classroom benefits, and work hard in teaching methods and mobilizing students' enthusiasm. In addition to cultivating students' self-evaluation skills, teachers should also combine with the encouraging evaluation. [8] Some studies have shown that the job burnout of rural primary and secondary school teachers in the eastern Henan region is more serious, [9] and some recent literature shows that the female teachers in primary and middle schools in Xinjiang Uygur Autonomous Region are also serious.[10] Teachers' negative emotions will inevitably affect students' learning status to a certain extent. Therefore, it is extremely urgent for teachers to carry out mental health training and business improvement.

In short, negative emotion, if not actively guided and solved for a long time, will affect learning significantly and cause some damage to the individual's body and mind, which will influence the individual's development and ultimately affect the construction of a harmonious society. Therefore, alleviating or eliminating the problem of school-weariness in primary and secondary schools is an arduous task and a social system project. The most fundamental thing is to reform the school's evaluation system and change the parents' educational concept.

\section{Conclusion}

(1) Anorexia is not only significantly affected by scholars' learning, but also causes certain damage to individuals' physical and mental health, which further affects their development. (2) It is a difficult task to alleviate or eliminate the boredom of primary and secondary school students. The fundamental task is to reform the school evaluation system and change the education concept of parents. (3) Positive psychology provides a new way to overcome the boredom of learning.

\section{References}

[1] Chen Qiang. A Probe into the Sources of Students' Learning Disgust in Schools[J].Hebei Education, (1):44 (2000)

[2] Sun Yunxiao. Mo is a maker of students who are tired of learning[J]. Children and Adolescents Research, (3): 62-63 (2000)

[3] Ren Jun. Positive Psychology[M] . Shanghai Education Press, 86-92 (2006)

[4] Chen Chen. Interventional study of positive psychology-oriented experiential career counseling for high school students' dislike of learning [D]. Central China Normal University, (2015)

[5] Lin Keqin. The Application of Positive Emotions in Classroom Teaching[J]. Journal of Guangxi Education Institute, (6): 125-126 (2001)

[6] Jiang Guangrong. Loss and Reversion of Humanity: Rogers' Humanistic Psychology [M]. Wuhan: Hubei Education Press, (2001)

[7] Chang Zhengqun. Research on Psychological Strategy of Effective Teaching in High School 
Chinese Classroom [D]. Liaoning Normal University, (2011)

[8] Xiao Haiping.Discussion on the Countermeasures to Overcome the Learning Disabilities of Primary and Middle School Students from the Perspective of Humanistic Psychology[J].Education Guide, (7):14-16 (2002)

[9] Wang Weihua. Investigation on the Burnout of Rural Primary and Secondary School Teachers in the East of Henan Province[J].Journal of Henan University of Science and Technology, 36(10):28-32 (2016)

[10]He Wen, Wang Wenlong. Investigation and Strategy Research on the Status Quo of Young Female Teachers' Job Burnout in Ethnic Minority Areas[J].Journal of Jilin Radio and Television University, (08):73-76 (2018) 